\title{
EDITORIAL
}

\section{La Eutanasia Justificada}

El 20 de mayo del presente año, la Honorable Corte Constitucional, "administrando justicia en nombre del pueblo y por mandato de la Constitución”, resolvió declarar exequible el artículo 326 del Código Penal, "con la advertencia de que en el caso de los enfermos terminales en que concurra la voluntad libre del sujeto pasivo del acto, no podrá derivarse responsabilidad para el médico autor, pues la conducta está justificada".

Para quienes no están familiarizados con nuestro Código Penal, el mencionado artículo 326 dice a la letra: "Homicidio por piedad. El que matare a otro por piedad, para poner fin a intensos sufrimientos provenientes de lesión corporal o enfermedad grave o incurable, incurrirá en prisión de seis meses a tres años". Como puede verse, la Corte Constitucional, además de mantener vigente la norma que castiga a quien le quite la vida a otro para librarlo de insoportables padecimientos, le da cauce legal al médico para practicar la eutanasia, a condición de que se trate de un enfermo en estado terminal y de que se lleve a cabo con su consentimiento.

Habida cuenta de que la sentencia de tan alto tribunal no estuvo precedida de pedimento alguno a favor de la eutanasia, ese pronunciamiento ha tomado por sorpresa al cuerpo médico y ha desencadenado, como era natural, una gran polémica a través de los distintos medios de información. Los círculos médicos y religiosos, por ser los más comprometidos, han dejado escuchar sus puntos de vista, quedando al descubierto que entre los cultores de la medicina existen dos corrientes: la que se opone de manera vehemente a su legalización y la que le otorga buen recibo.

No faltará quien se pregunte: “¿Es acaso ético que un médico esté del lado de quienes aceptan la práctica de la eutanasia?" No es de extrañar que se cuestione dicho criterio, pues desde hace veinticinco siglos se nos identifica con los enemigos de la muerte, es decir, con los defensores incondicionales de la vida. Recuérdese que la medicina occidental, desde sus inicios, recibió el influjo técnico y moral de la llamada "Escuela hipocrática", que floreció casi quinientos años antes de Cristo, en la edad dorada de Atenas. En efecto, para entonces habian caído en el desprestigio todos quienes ejercían al arte de curar, incluyendo a los discípulos y seguidores de Hipócrates. Dado que no existían reglamentos oficiales que establecieran requisitos para desempeñar el oficio de curador, cualquiera, motu proprio, podía declararse médico. El resultado de tal libertinaje fue la pérdida de la confianza hacia los sanadores por parte de la sociedad, puesto que sentía amenazados dos de sus bienes más preciados: la salud y la vida.

Para rescatar esa confianza, los líderes de la escuela hipocrática dieron a la circulación un documento en el que se comprometían, poniendo a sus dioses como garantes, a no hacerles nunca daño a sus pacientes y a velar solícitamente por sus vidas. Ese documento, conocido por la posteridad con el nombre de Juramento Hipocrático, vino a constituirse desde entonces en la tabla de la ley para quienes profesaran en las disciplinas médicas. Así las cosas, la vida humana adquirió un muy elevado concepto, tanto como para alcanzar la categoría de don divino. En otras palabras, quedó sacralizada, excluida como pertenencia particular o de terceros. Ese concepto, venido de la medicina hipocrática, fue apuntalado posteriormente por influjo de la religión judeo-cristiana. Nadie, distinto a Dios, puede disponer de la vida.

La ética médica tradicional, fundamentada en principios paternalistas, comenzó a resquebrajarse cuando el concepto de autonomía adquirió validez jurídica, como también moral. El individuo sólo llega a ser persona cuando está en capacidad de autogobernarse. Quien puede reflexionar acerca de la bondad o maldad de sus actos, es sujeto moral y jurídico. Cada cual es dueño de sí mismo, mientras pueda administrarse conscientemente. Nada ni nadie debe interferir ese proceso. Como producto de tal concepción, la libertad individual adquirió carta de ciudadanía, a condición de que su ejercicio no fuera a atentar contra los intereses y derechos de los demás. 
La práctica de la medicina hubo de sujetarse a tal principio. En efecto, la autonomía del enfermo entró a gravitar en la relación médico-paciente, constituyéndose hoy día en la norma moral y jurídica de mayor trascendencia, de obligatoria consideración por parte de quienes nos dedicamos al arte de curar. Si el principio de beneficencia fue el fundamento básico de la ética hipocrática, la autonomía vino a ocupar su lugar, o, por lo menos, a compartir con él su importancia. Compete solo al paciente decidir qué es lo que más conviene a sus intereses, vale decir, a su salud y a su vida. Ya no es el médico quien de manera autónoma lo determina, como ocurrió durante veinticinco siglos, atendiendo las recomendaciones de la escuela hipocrática. El enfermo como incompetente mental y el médico como déspota ilustrado, quedaron relegados en virtud del principio de autonomía.

Precisamente, dicho principio es el que ha invocado nuestra Corte Constitucional para darle validez jurídica a la eutanasia. Si el enfermo, desahuciado ya por la ciencia médica, considera que no tiene ningún sentido soportar las agonías de un proceso inevitable, puede, echando mano de su libre voluntad, solicitar de su médico que le ponga dulce fin a sus padecimientos. Entonces - dice la Corte- "no podrá derivarse responsabilidad para el médico autor, pues la conducta está justificada".

No obstante llegara a adquirir plena vigencia la sentencia de la Corte-como que en la actualidad está siendo reconsiderada su rectitud procedimental-, la juridicidad de la eutanasia no obligaría a todos los médicos a practicarla. La autonomía vuelve a invocarse, esta vez a favor del facultativo. La ética en general, más que un asunto de normas jurídicas o religiosas, es algo que atañe exclusivamente con la conciencia individual. En ética médica-que es el tema que utilizo como fondo del presente escrito- la moralidad del acto profesional no está dada por la sujeción a las normas o códigos específicos de comportamiento, sino por lo que dicte la conciencia de cada quien. Recordemos que para los antiguos griegos el ethos era un lugar reservado, donde el hombre, solitario, rumia sus intenciones. Ese reservado, que es la conciencia, corresponde a un grupo de neuronas cerebrales, sujetas al influjo de autoneurotransmisores.

El llamado "homicidio por piedad", del que se ocupa el artículo 326 del Código Penal, es, sin duda, la eutanasia misma, pero no todos los homicidios por piedad quedan cobijados por el manto eutanásico. La eutanasia, en su prístino sentido, significa ocasionar la muerte de una manera buena, apacible, para ponerle fin a una existencia indigna, producto de una enfermedad intratable. $Y$ el homicidio por piedad no se acompaña siempre de esas connotaciones. En la eutanasia el sujeto activo es el médico, u otro profesional del campo de la salud, que se supone conoce bien las formas de conducir a la muerte sin ocasionar dolor ni temor. Además, en el homicidio por piedad puede estar ausente la solicitud expresa del sujeto pasivo, es decir, puede llevarse a cabo sin mediar su autorización, desconociéndose el principio de autonomía. De ahí que -en el supuesto de quë la sentencia de la Corte Constitucional llegara al Congreso para convertirla en ley- tendrían que contemplarse muchas consideraciones situacionales, para cerrarles el paso a equivocadas o proclives interpretaciones.

Sea lo que fuere, la eventual legalización de la eutanasia nos coloca a los médicos en una posición incómoda frente a la sociedad. La circunstancia de que el Estado, a través de sus legisladores, nos conceda licencia para acabar con la vida de nuestros pacientes, puede arrojar una sombra de duda sobre nuestro comportamiento, no importa que esa autorización esté inteligentemente condicionada.

Para mayor ilustración de mis colegas ginecobstetras, considero pertinente aclarar algunos términos que están circulando en la actualidad, dada la importancia que ha adquirido el tema de la eutanasia.

La eutanasia ha sido considerada como "activa” y "pasiva”, según el papel desempeñado por el médico, o la persona que la practique. La activa, como ya señalé, es una forma de homicidio piadoso, caracterizada por el suministro o aplicación de sustancias letales por parte del sujeto activo. En otras palabras, es precipitar el final, darle paso a una muerte contenida. Si el médico ha sido ese sujeto activo, puede hablarse de "iatrotanasia". 
El término "eutanasia pasiva" se ha prestado para interpretaciones equivocadas y, por lo mismo, para discusiones de carácter moral y jurídico. Muchos la identifican con la suspensión de medidas extraordinarias, y aún ordinarias (hidratación, por ejemplo), vale decir, dejando que la muerte llegue, sin apresurarla directamente. Adquiera validez, invocando el principio moral del doble efecto, el empleo liberal de sedantes y analgésicos, no importa que con ellos se coloque al enfermo en los linderos de la muerte. Si ésta ocurre, no hubo intención de causarla. Se practicó la eutanasia en forma involuntaria, indirecta. Interpretando en esa forma lo que significa "eutanasia pasiva" se ha echado mano de un eufemismo para tranquilizar la conciencia del sujeto activo y para hacerle un esguince a la ley penal. Con razón el filósofo James Rachels ha dicho que las doce formas de eutanasia-la activa y la pasiva-se mantienen moralmente juntas o se hunden juntas.

Tengo para mí que la eutanasia pasiva es el mismo "suicidio asistido". El médico desempeña un papel indirecto, pero interviene en el proceso eutanásico. Es, sin duda, un homicidio indirecto por piedad; ayudado a ruego del paciente, es decir, atendiendo la autonomía de éste. El médico está igual de comprometido que en la eutanasia activa, no obstante se haya abstenido de poner en marcha el mecanismo letal.

Aunque la Corte Constitucional no lo menciona, el suicidio asistido también quedaría amparado legalmente.

"Morir dignamente" es un término que advino para contrarrestar el llamado encarnizamiento terapéutico, o "distanasia", que no es otra cosa que la soberbia y prepotencias médicas puestas al servicio de una causa equivocada y criticable: no dejar morir al enfermo desahuciado, invocándose el papel de luchador contra la muerte asignado al médico desde la época hipocrática. Por supuesto que tras esta actitud aparentemente ética se esconden intenciones proclives, casi siempre relacionada con afán de lucro. El movimiento pro Derecho a Morir Dignamente, que es ya una institución universal, aboga por un final sin dolor, sin angustia, utilizando los recursos que ofrecen los denominados "cuidados paliativos". Si se acata el principio de autonomía del paciente, y de hacer carrera la eutanasia justificada, ésta entraría a formar parte del morir con dignidad.

Por último, debo mencionar la "ortotanasia", identificada también por algunos con la "eutanasia pasiva". En mi concepto, la ortotanasia es el curso espontáneo, sin ninguna interferencia, de un proceso patológico que llevará indefectiblemente hacia la muerte. Aquí no tienen cabida los cuidados paliativos. En otras palabras, es el abandono completo del paciente terminal, la antitesis del encarnizamiento terapéutico. Recuérdese que la distanasia es patrimonio de personajes famosos, pudientes económicamente, en tanto que la ortotanasia o abandono total lo es de los huérfanos de toda fortuna.

\section{FERNANDO SANCHEZ TORRES*}

* Miembro Emérito de la Sociedad Colombiana de Obstetricia y Ginecología. Presidente del Instituto Colombiano de Estudios Bioéticos. Jefe de la División de Educación de la Asociación Colombiana de Facultades de Medicina. 